\title{
Article
}

\section{Oxygen Sparing Effect of Bacteriotherapy in COVID-19}

\author{
Giancarlo Ceccarelli ${ }^{1} \mathbb{D}$, Massimiliano Marazzato ${ }^{1, *}$, Luigi Celani ${ }^{1}$, Francesca Lombardi ${ }^{2}{ }^{\infty}$, Alessandra Piccirilli ${ }^{3}$, \\ Massimo Mancone ${ }^{4}$, Vito Trinchieri ${ }^{1}$, Francesco Pugliese ${ }^{5}$, Claudio M. Mastroianni ${ }^{1}$ and Gabriella d'Ettorre ${ }^{1}$ (i)
}

1 Department of Public Health and Infectious Diseases Sapienza, University of Rome, 00185 Rome, Italy; giancarlo.ceccarelli@uniroma1.it (G.C.); luigi.celani@uniroma1.it (L.C.); vito.trinchieri@uniroma1.it (V.T.); claudiomaria.mastroianni@uniroma1.it (C.M.M.); gabriella.dettorre@uniroma1.it (G.d.)

2 Department of Life, Health \& Environmental Sciences, University of L'Aquila, 67100 L'Aquila, Italy; francesca.lombardi@univaq.it

3 Department of Biotechnological and Applied Clinical Sciences, University of L'Aquila, 67100 L'Aquila, Italy; alessandra.piccirilli@univaq.it

4 Department of Clinical Internal Anesthesiologic and Cardiovascular Sciences Sapienza, University of Rome, 00185 Rome, Italy; massimo.mancone@uniroma1.it

5 Department of Anesthesia and Intensive Care Medicine, Sapienza University of Rome, 00185 Rome, Italy; francesco.pugliese@uniroma1.it

* Correspondence: massimiliano.marazzato@uniroma1.it

Citation: Ceccarelli, G.; Marazzato, M.; Celani, L.; Lombardi, F.; Piccirilli, A.; Mancone, M.; Trinchieri, V.;

Pugliese, F.; Mastroianni, C.M.; d'Ettorre, G. Oxygen Sparing Effect of Bacteriotherapy in COVID-19. Nutrients 2021, 13, 2898. https:// doi.org/10.3390/nu13082898

Academic Editor: Leyuan Li

Received: 11 July 2021

Accepted: 21 August 2021

Published: 23 August 2021

Publisher's Note: MDPI stays neutral with regard to jurisdictional claims in published maps and institutional affiliations.

Copyright: (c) 2021 by the authors. Licensee MDPI, Basel, Switzerland. This article is an open access article distributed under the terms and conditions of the Creative Commons Attribution (CC BY) license (https:/ / creativecommons.org/licenses/by/ $4.0 /)$.

\begin{abstract}
Background: We previously reported that severe COVID-19 patients had higher chances of survival and a reduced risk of developing respiratory failure when administered with the probiotic formulation SLAB51. This study aimed to investigate further bacteriotherapy mechanisms and how early they are activated. Methods: We performed an analysis on the blood oxygenation parameters collected in sixty-nine severe COVID-19 patients requiring non-invasive oxygen therapy and presenting a CT lung involvement $\geq 50 \%$. Twenty-nine patients received low-molecular-weight heparin, azithromycin and Remdesivir. In addition, forty subjects received SLAB51. Blood gas analyses were performed before the beginning of treatments and at $24 \mathrm{~h}$. Results: The patients receiving only standard therapy needed significantly increased oxygen amounts during the $24 \mathrm{~h}$ observation period. Furthermore, they presented lower blood levels of $\mathrm{pO}_{2}, \mathrm{O}_{2} \mathrm{Hb}$ and $\mathrm{SaO}_{2}$ than the group also supplemented with oral bacteriotherapy. In vitro data suggest that SLAB51 can reduce nitric oxide synthesis in intestinal cells. Conclusions: SARS-CoV-2 infected patients may present lesions in the lungs compromising their gas exchange capability. The functionality of the organs essential for these patients' survival depends mainly on the levels of $\mathrm{pO}_{2}, \mathrm{O}_{2} \mathrm{Hb}$ and $\mathrm{SaO}_{2}$. SLAB51 contains enzymes that could reduce oxygen consumption in the intestine, making it available for the other organs.
\end{abstract}

Keywords: COVID-19; SLAB51; probiotics; nitric oxide; hypoxia

\section{Introduction}

The role of oral bacteriotherapy in the armamentarium for fighting the COVID-19 pandemic is under scrutiny [1-3]. In a previous retrospective study of 200 patients, we showed that subjects treated with a specific formulation of bacteria (SLAB51) had a significantly higher chance of survival [4]. Moreover, we reported that the risk of developing respiratory failure for a patient is reduced eightfold by administering SLAB51 in addition to the routinely used therapy (RUT) [5].

The present work aimed to investigate further SLAB51's short-term action in alleviating the respiratory conditions in subjects presenting SARS-CoV-2 infections. To this end, we examined the response of two groups of patients, one treated with RUT and one with RUT and bacteriotherapy twenty-four hours after the product's initial administration. We offer evidence that SLAB51 contains bacteria endowed with arginine deiminase activity (ADI), which catalyzes L-arginine's hydrolysis to citrulline and ammonia. ADI inhibits the 
arginine-dependent synthesis of nitric oxide (NO). This gas is a signaling molecule for the innate inflammatory immune response and modulates intestinal vasodilation. Furthermore, ADI, by depleting arginine, may exert antiviral activity against some viruses, including SARS-CoV-2, and decrease the hyperinflammatory lung damage characteristics of patients with severe COVID-19 [6,7].

\section{Materials and Methods}

\subsection{Design of the Study, Population, Settings and Data Collection}

This study is a "real life" prospective analysis of adult (>18 years) SARS-CoV-2 infected patients supported with oxygen therapy progressively hospitalized between October 2020 and December 2020 in the Policlinico Umberto I, University "Sapienza", Rome, Italy.

The patients included in the study were hosted in two different wards devoted to the management of COVID-19: in the first ward, a clinical therapeutic strategy including ad interim routinely used therapy associated with SLAB51 bacteriotherapy supplementation was adopted (RUT+OB group), while in the second ward, only RUT was administered (Figure 1). The two wards had similar characteristics regarding the type of hospitalized patients and the expertise of the healthcare personnel. Inclusion criteria were patients $>18$ years old, a diagnosis of COVID-19, a need of oxygen support and a CT scan confirming diagnosis of SARS-CoV-2 related pneumonia. Exclusion criteria were pregnancy, other previous chronic $\mathrm{CT}$ chest diseases such as pulmonary edema and interstitial lung disease. All patients clinically diagnosed with COVID-19 underwent a high-resolution CT/noncontrast enhanced chest CT at admission in the hospital. Two multidetector CT scanners (Somatom Sensation 16 and Somatom Sensation 64; Siemens Healthineers) were used for all examinations. Radiologists, experts in thoracic imaging, performed the CT image analysis assessing location and distribution of the disease and CT chest findings. A semiquantitative CT score was calculated based per each of the 5 lobes considering the extent of anatomic involvement, as follows: 0 , no involvement; $1,<5 \%$ involvement; $2,5-25 \%$ involvement; 3, 26-50\% involvement; 4, 51-75\% involvement; and 5, >75\% involvement. The resulting global CT score was the sum of each individual lobar score (0 to 25). The sources for patient data were medical records stored in the electronic information system of the wards involved. The variables considered included: (1) anamnestic data, (2) past clinical history (comorbidities) and (3) current clinical history, treatment and laboratory data. The study's primary endpoint was the evaluation of differences in partial pressure of oxygen $\left(\mathrm{pO}_{2}\right)$, oxygenated hemoglobin $\left(\mathrm{O}_{2} \mathrm{Hb}\right)$ and the percentage of hemoglobin saturated with oxygen $\left(\mathrm{SaO}_{2}\right)$ at baseline (T0) and after $24 \mathrm{~h}$ from the start of therapy (T1) in the two groups to confirm/refute previous observations [5]. The arterial blood gas (ABG) test was performed using the blood drawn from the radial artery while the fraction of inspired oxygen $\left(\mathrm{FiO}_{2}\right)$ as well as the amount of supplied oxygen $(\mathrm{L} / \mathrm{min})$ were also registered. In case of achievement of the primary outcome, the secondary endpoint was to evaluate whether the improvement of arterial blood oxygenation parameters in patients treated with bacteriotherapy was due to SLAB51's action in the intestine. In some patients, a blood sample was obtained after 5-6 h from the bacteriotherapy administration to evaluate how early the phenomenon was occurring. 


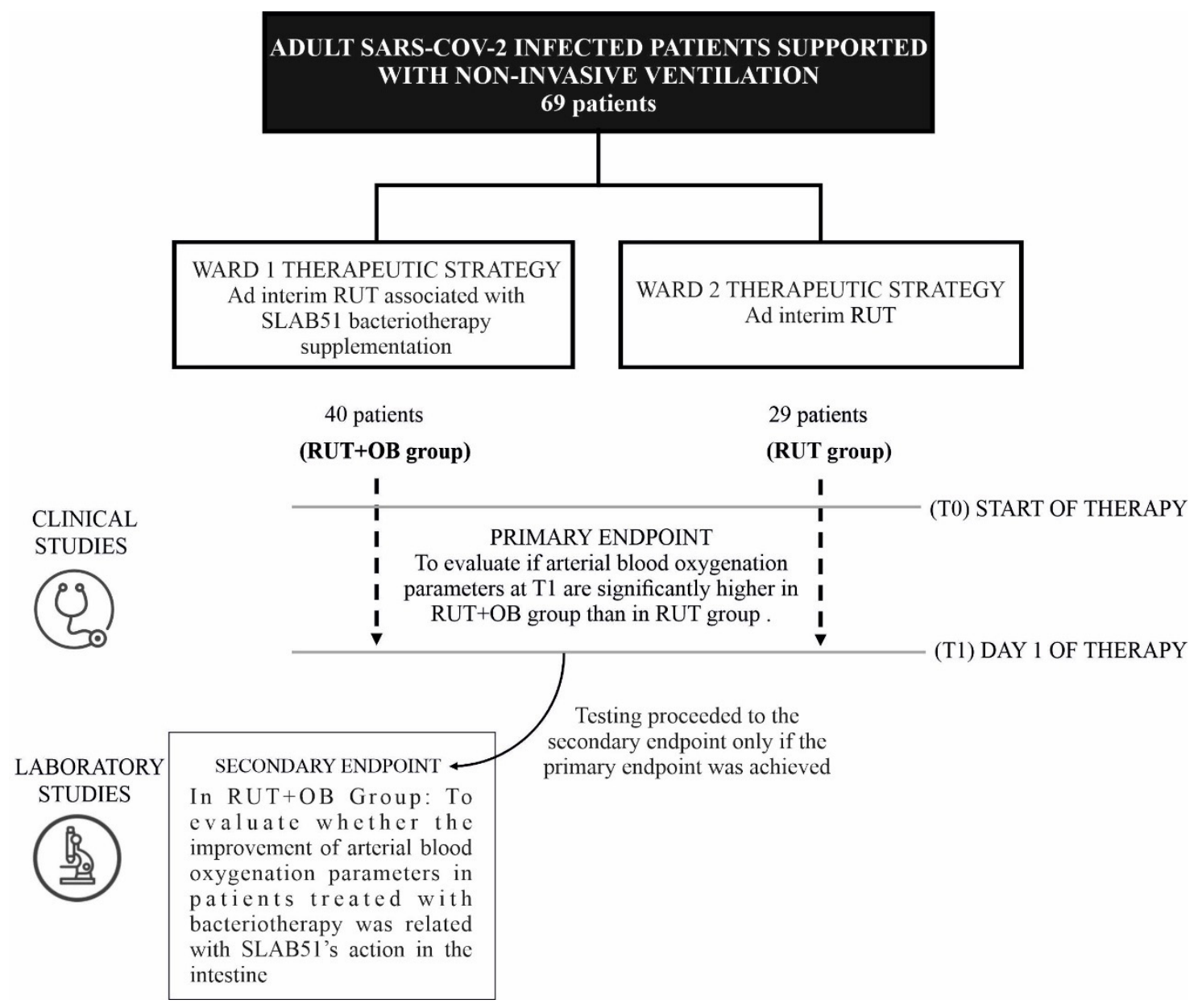

Figure 1. Schematic representation of the study design.

\subsection{Diagnosis of SARS-CoV-2 Infection}

The diagnosis of SARS-CoV-2 infection was defined as one positive oropharyngeal and nasopharyngeal swab performed in duplicate for SARS-CoV-2 E and S gene by a reverse transcriptase-polymerase chain reaction (RT-PCR).

\subsection{COVID-19 Treatments}

The patients were treated with ad interim RUT as suggested by the provisional guidelines of the Italian Society of Infectious and Tropical Diseases (SIMIT) and the Italian Medicine Agency (AIFA). In detail: Dexamethasone (6 mg daily for 10 days) plus low molecular weight heparins (prophylactic dosage) \pm azithromycin (500 mg daily); Remdesevir, as per AIFA guidelines. Bacteriotherapy (SLAB51) was administered in three equal doses per day for a total of 2400 billion bacteria per day. SLAB51 contains Streptococcus thermophilus DSM 32245, Bifidobacterium lactis DSM32246, Bifidobacterium lactis DSM 32247, Lactobacillus acidophilus DSM 32241, Lactobacillus helveticus DSM 32242, Lactobacillus paracasei DSM 32243, Lactobacillus plantarum DSM 32244 and Lactobacillus brevis DSM 27961 (Sivomix $8000^{\circledR}$, Ormendes SA, Lausanne, Switzerland).

\subsection{Supplemental Oxygen}

All patients included in the study were supported by oxygen therapy delivered via Venturi masks in spontaneous breathing patients. 


\subsection{Ethics Committee Approval}

Reporting of the study conforms to broad EQUATOR guidelines. The Ethics Committee of Policlinico Umberto I approved the study with number 109/2020.

\subsection{Arginine Deiminase (ADI) Assay}

SLAB51 was suspended at the concentration of $133 \times 10^{9} \mathrm{CFU}$ in $10 \mathrm{~mL}$ of phosphate buffered saline (PBS, EuroClone, West York, UK). ADI activity was analyzed by the amount of citrulline formed from arginine by measuring colour changes due to the products formed by diacetyl-mono-oxime as previously described [8].

\subsection{Cell Line, Culture Condition and Treatment}

Human colon adenocarcinoma-derived $\mathrm{CaCo}-2$ cell lines purchased from SigmaAldrich (St. Louis, MO, USA) were maintained in culture in DMEM supplemented with $10 \%$ FCS, $1 \%$ non-essential aminoacid, $1 \mathrm{mM}$ sodium pyruvate and $2 \mathrm{mM}$ L-glutamine, $100 \mathrm{U} / \mathrm{mL}$ penicillin and $100 \mu \mathrm{g} / \mathrm{mL}$ streptomycin (EuroClone, West York, UK). After reaching $80 \%$ confluence cells were seeded into a sterile tissue culture 12-well plate (Becton Dickinson, San Jose, CA, USA) at 40,000 cells $/ \mathrm{cm}^{2}$ and allowed to attach overnight. The cells were then treated for $24 \mathrm{~h}$ with or without nitric oxide synthase 2 (NOS2) inhibitor $\mathrm{N}$-(3-(aminomethyl) benzyl) acetamidine (1400 W) (Sigma-Aldrich, Saint Louis, MO, USA) $(100 \mu \mathrm{M})$, ADI inhibitor formamidine hydrochloride (Sigma-Aldrich) $(10 \mathrm{mM})$ or SLAB51 $\left(10^{7} \mathrm{CFU} / \mathrm{mL}\right.$, suspended at the concentration of $133 \times 10^{9} \mathrm{CFU}$ in $10 \mathrm{~mL}$ of phosphate buffered saline (PBS) (EuroClone, West York, UK). Where specified, a SLAB51 sample was preincubated for $30 \mathrm{~min}$ with or without formamidine $(100 \mathrm{mM})$. No significant influence on the cell viability compared to the control cells was registered after the treatment with SLAB51, $1400 \mathrm{~W}$ and formamidine, as evaluated by Trypan blue assay.

\subsection{Total RNA Extraction and NOS2 Expression by RT-PCR}

Total RNA from CaCo-2 cells was extracted using TRIzol reagent according to the manufacturer's protocol. RNA for NOS2 positive control was obtained from murine macrophage RAW 264.7 cells (Sigma-Aldrich) treated with IFN- $\gamma 100 \mathrm{ng} / \mathrm{mL}$ and LPS $1 \mu \mathrm{g} / \mathrm{mL}$. Negative control was represented by acute human T leukemia-derived Jurkat cells (ATCC). RT-PCR was performed as previously described [9]. All PCR reagents and EuroSafe Nucleic Acid Staining Solution were acquired from EuroClone. Primers were acquired from IDT (Integrated DNA Technologies, Coralville, IA, USA). The RT-PCR reaction was made by the Thermocycler GeneAmp PCR System 9700 (Applied Biosystems, Foster City, CA, USA). PCR quantification was performed by densitometer (UVItec Limited BTS $-20 \mathrm{M}$, Cambridge, UK) and the densitometric analysis was made using ImageJ software. The primers used for NOS2 and beta-actin amplification were as follows: NOS2 FOR5'CTGACGGGAGATGAGCTC- $3^{\prime}$; NOS2 REV5'-AGTCGTGCTTGCCATCACTC- $3^{\prime}$; $\beta$-actin FOR5'-AGCGGGAAATCGTGCGTG-3'; $\beta$-actin REV5'-CAGGGTACATGGTGGTGCC-3'

\subsection{Nitrite Level Assay}

The enzymatic activity of NOS2 was evaluated by measuring nitrite levels using nitrate reductase and the Griess reaction through a colorimetric assay (Nitrite Assay kit, Sigma-Aldrich Co., Milan, Italy) in the supernatants of $\mathrm{CaCo}-2$ cells, treated as described, according to the manufacturer's instructions.

\subsection{Statistical Analysis}

No sample size calculations were performed. The categorical variables were compared using the $\chi 2$ test with Yates' continuity correction and showed as absolute frequencies and percentage. The bilateral Mann-Whitney $U$ test was used for continuous variables to determine statistically significant differences between groups at each considered time points, while for each group the Wilcoxon test was used to assess significant differences between consecutive time points. For nitrite levels, the non-parametric Kruskal-Wallis 
test followed by Dunn's post hoc test were used to evaluate statistical significance among tested conditions. In each case, a $p$ value $\leq 0.05$ was considered statistically significant. Analyses were performed by using the statistical software R 4.0.3 [10].

\section{Results}

\subsection{Primary Endpoint}

Data were collected and compared between COVID-19 positive patients who received RUT plus oxygen $(29 ; 42 \%)$ and subjects who were also treated with oral bacteriotherapy $(40 ; 58 \%)$ plus oxygen. The main characteristics of both groups of patients are summarized in Table 1.

Table 1. Population stratified in two groups according to the therapy: RUT or RUT plus oral bacteriotherapy. IQR: interquartile range $\left(25^{\circ}-75^{\circ}\right)$.

\begin{tabular}{|c|c|c|c|c|c|}
\hline \multirow[t]{2}{*}{ Parameter } & \multicolumn{2}{|c|}{ RUT (No. = 29) } & \multicolumn{2}{|c|}{ RUT + OB (No. = 40) } & \multirow[t]{2}{*}{$p$-Value } \\
\hline & Median (IQR) & No. (\%) & Median (IQR) & No. (\%) & \\
\hline Age (years) & $70(60-77)$ & & $61(51-74 \cdot 3)$ & & 0.09 \\
\hline Sex (Male) & & $25(86 \cdot 2)$ & & $22(55)$ & 0.01 \\
\hline $\mathrm{BMI}-\mathrm{kg} / \mathrm{m}^{3}$ & $20(20-22)$ & & $20(18 \cdot 8-22)$ & & 0.47 \\
\hline Alanine aminotransferase (ALT)-IU/L & $25(18-40)$ & & $30(23 \cdot 5-45)$ & & 0.17 \\
\hline Aspartate aminotransferase (AST)-IU/L & $21(19-38)$ & & $26(18-36.3)$ & & 0.95 \\
\hline CT score & $16.5(15-18)$ & & $\begin{array}{c}16.5(15-18) \\
5\end{array}$ & & 0.91 \\
\hline Charlson index & $3(1-4)$ & & $1(1-5)$ & & 0.24 \\
\hline Drug therapy & & & & & \\
\hline Antiviral (Remdesivir) & & $10(34.4)$ & & $8(20)$ & 0.28 \\
\hline Antibiotic & & $25(86.2)$ & & $39(97.5)$ & 0.19 \\
\hline
\end{tabular}

Except for sex, at baseline, the two groups determined on the base of SLAB51 administration were homogeneous for all the considered variables comprising the SARS-CoV-2 drug therapies, the $\mathrm{pO}_{2}$ levels, the $\mathrm{pO}_{2} / \mathrm{FiO}_{2}$ ratio and the amount of administered oxygen (median; IQR RUT 4; 1-6 L/min; RUT+OB 1.5; 1-6 L/min, $p=0.31$ ). After $24 \mathrm{~h}$ from the first dose of SLAB51, the RUT+OB group showed significantly higher values of the $\mathrm{pO}_{2} / \mathrm{FiO}_{2}$ ratio $(p=0.002)$ and $\mathrm{pO}_{2}(p=0.01)$ than the RUT group, evidencing improved conditions (Figure 2a,b). Concerning the $\mathrm{FiO}_{2}$ values, at the beginning of the observation period the two groups were homogeneous while, at the $24 \mathrm{~h}$ endpoint, significantly higher $\mathrm{FiO}_{2}$ levels were registered for the RUT group than the RUT+OB one $(p=0.002)$ (Figure 2c). An analysis of $\mathrm{O}_{2} \mathrm{Hb}$ and $\mathrm{SaO}_{2}$ levels yielded results in line with those previously described for the $\mathrm{pO}_{2}$ and $\mathrm{pO}_{2} / \mathrm{FiO}_{2}$ ratio with significantly higher values registered for the RUT+OB group respective to the group receiving only standard therapy $\left(\mathrm{O}_{2} \mathrm{Hb}, p=0.006 ; \mathrm{SaO}_{2}, p=0.038\right)$ (Figure 2e,f). Notably, after $24 \mathrm{~h}$ from the beginning of treatment, the group administered with SLAB51 presented better blood oxygenation levels than the group receiving only the standard therapy, despite the fact that the RUT group registered a significantly higher increase in the amount of supplied oxygen over time $(p=0.002)$ (Figure 2d). Finally, the two groups were homogeneous for glycemia, lactates and hematocrit levels both at the start of treatment and at the following $24 \mathrm{~h}$ (Figure $2 \mathrm{~g}-\mathrm{i}$ ).

We were also able to obtain data relative to $6 \mathrm{~h}$ from the start of treatments in a few subjects treated with RUT or RUT $+\mathrm{OB}$. The $\mathrm{pO}_{2} / \mathrm{FiO}_{2}$ ratio, $\mathrm{pO}_{2}, \mathrm{SaO}_{2}$ and $\mathrm{O}_{2} \mathrm{Hb}$ improved in the RUT+OB group and were unchanged or worsened in the RUT group. (Table 2).

The hospital registry allowed us to see how the disease progressed in patients treated with RUT or RUT + OB during their hospitalization over the following weeks. Four (13.8\%) patients treated with RUT were transferred to the ICU due to worsening respiratory conditions. In addition, one of these patients died. Only one (2.5\%) patient treated with RUT and oral bacteriotherapy developed a clinical picture that necessitated transfer to the ICU, and no subject in this group died. 
a

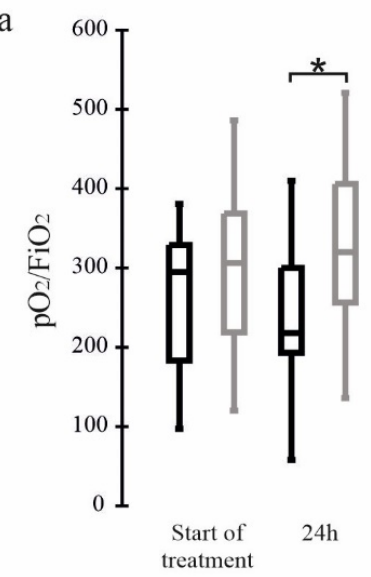

b

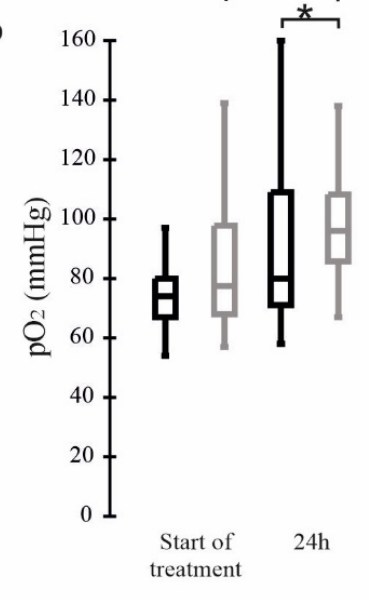

c

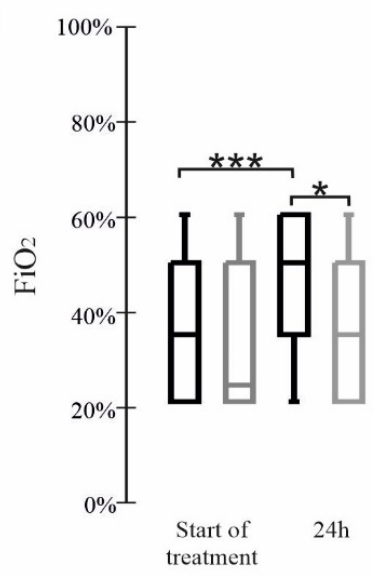

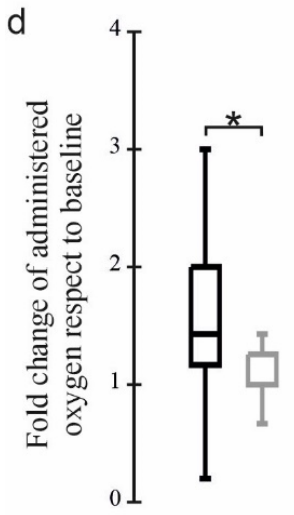

e
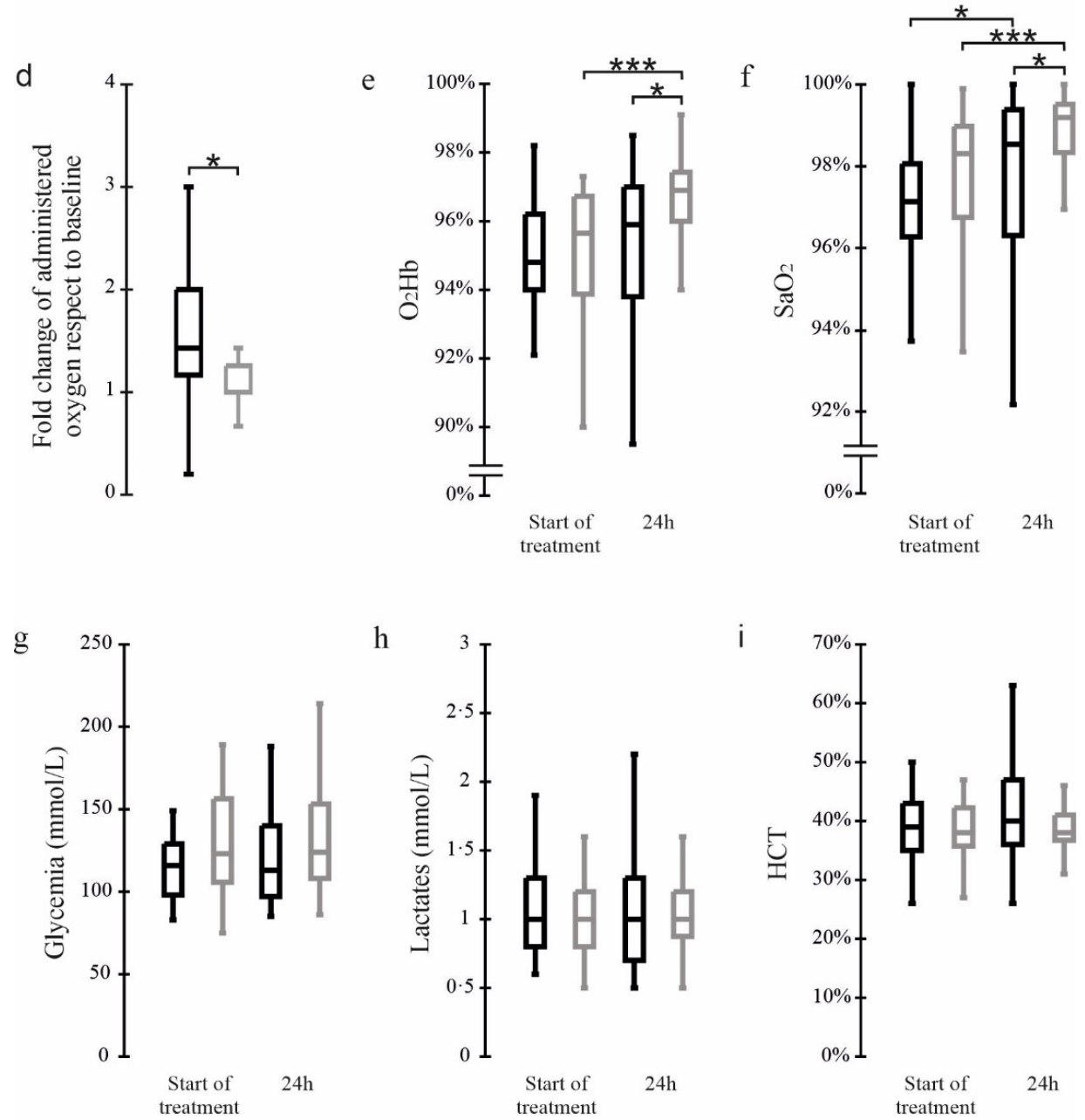

h
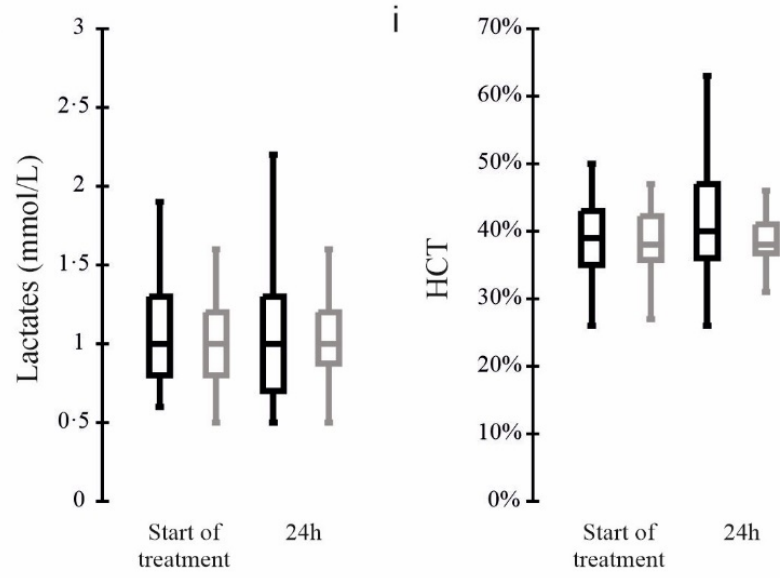

RUT

RUT $+\mathrm{OB}$

Figure 2. Results of blood gas analyses. Box end whiskers plots showing the value distribution of (a) $\mathrm{PO}_{2} / \mathrm{FiO}_{2}$ ration, (b) $\mathrm{pO}_{2}$, (c) $\mathrm{FiO}_{2}$, (d) Fold change of administered oxygen respect to baseline, (e) $\mathrm{O}_{2} \mathrm{Hb}$, (f) $\mathrm{SaO}_{2}$, (g) glycemia, (h) lactates, and (i) HTC obtained by routine laboratory analysis. Where present, statistical significance has been reported between RUT and RUT+OB groups at each time point, as well as for each group over time. ${ }^{*}: p \leq 0.05 ;{ }^{* *}: p \leq 0.001 ;{ }^{* * *}: p \leq 0.0001$. 
Table 2. Blood parameters obtained by routine laboratory analysis at $6 \mathrm{~h}$ from the start of treatment. Representative patients belonging to both groups were reported.

\begin{tabular}{|c|c|c|c|c|c|c|c|c|c|c|c|}
\hline & & \multicolumn{2}{|c|}{$\mathrm{pO}_{2} / \mathrm{FiO}_{2}$} & \multicolumn{2}{|c|}{$\mathrm{pO}_{2}(\mathrm{mmHg})$} & \multicolumn{2}{|c|}{$\mathrm{FiO}_{2}(\%)$} & \multicolumn{2}{|c|}{$\mathrm{O}_{2} \mathrm{Hb}(\%)$} & \multicolumn{2}{|c|}{$\mathrm{SaO}_{2}(\%)$} \\
\hline & & $\mathbf{O h}$ & $6 \mathrm{~h}$ & $0 \mathrm{~h}$ & $6 \mathrm{~h}$ & $0 \mathrm{~h}$ & $6 \mathrm{~h}$ & $\mathbf{O h}$ & $6 \mathrm{~h}$ & $0 \mathrm{~h}$ & $6 \mathrm{~h}$ \\
\hline \multirow{2}{*}{ RUT } & Patient 1 & 319 & 278 & 96 & 63 & 21 & 28 & 96.6 & 92 & 98 & 93 \\
\hline & Patient 2 & 310 & 175 & 65 & 35 & 21 & 40 & 93 & 94.2 & 98.8 & 98.2 \\
\hline \multirow{2}{*}{$\mathrm{RUT}+\mathrm{OB}$} & Patient 3 & 352 & 390 & 76 & 86 & 21 & 21 & 95.3 & 96.9 & 96.9 & 98.9 \\
\hline & Patient 4 & 328 & 354 & 69 & 89 & 21 & 21 & 82 & 96 & 96 & 98 \\
\hline
\end{tabular}

\subsection{Secondary Endpoint}

The enzymatic activity of ADI expressed as nmol/100 $\mu \mathrm{L}$ citrulline levels was first analyzed at different concentrations of the SLAB51 sample at one-hour incubation. The results showed that the ADI activity was proportional to the SLAB51 amount, as shown in Figure 3a. The test was repeated with a fixed concentration of bacterial suspension $\left(6 \times 10^{7} \mathrm{CFU} / 100 \mu \mathrm{L}\right)$ and evaluated at 10-min intervals, thus highlighting that the ADI activity of whole bacteria was stable and linear over assay time; of interest, the capacity of the enzyme to convert arginine in citrulline was detectable as early as a few minutes (Figure 3b).

a

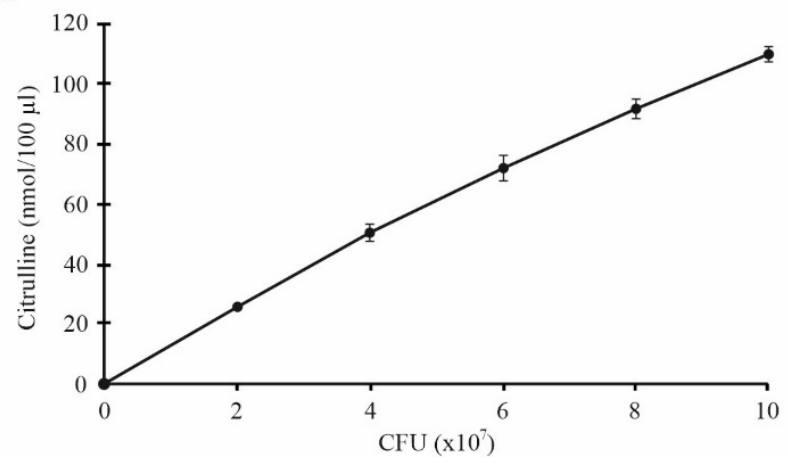

$\mathrm{b}$

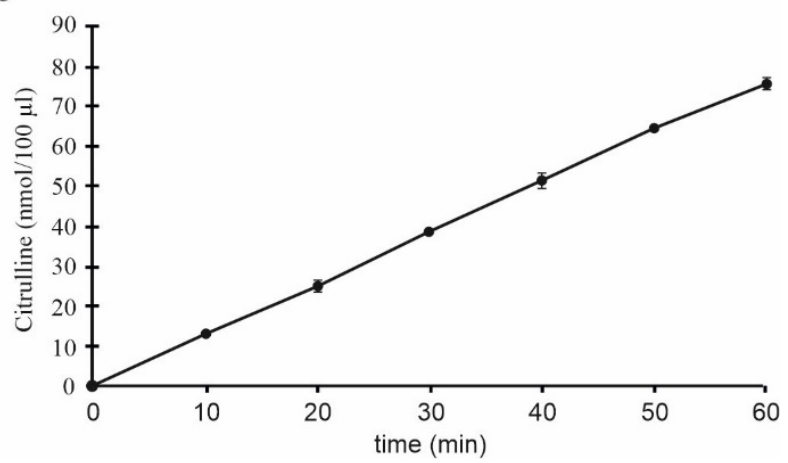

Figure 3. ADI activity in SLAB51 sample. (a) Citrulline levels (nmol/100 $\mu \mathrm{L})$ after $1 \mathrm{~h}$ incubation with different amounts of SLAB51 suspension $\left(\times 10^{7} / 100 \mu \mathrm{L}\right)$; (b) kinetics of ADI activity of SLAB51 at $6 \times 10^{7} \mathrm{CFU} / 100 \mu \mathrm{L}$. Data are expressed as mean of two measurements \pm SD.

We next tested the ability of SLAB51 to inhibit NOS2 activity, using the human colon adenocarcinoma-derived CaCo-2 cells, which constitutively express high levels of NOS2 as shown by the RT-PCR analysis (Figure 4a), thus confirming previous reports [11]. The NO release in CaCo-2 cells after $24 \mathrm{~h}$ was measured as nitrites levels $(\mu \mathrm{M})$ in culture medium and expressed as a percentage of nitrite levels vs. control (Figure 4b). Exposure to $1400 \mathrm{~W}$, one of the most potent and selective NOS2 inhibitors was used to control NOS2 inhibition in our experimental model positively. As expected, $1400 \mathrm{~W}$ significantly reduced nitrite levels [12]. SLAB51 treatment reduced NO release to a level comparable to that of $1400 \mathrm{~W}$ at $24 \mathrm{~h}$. To investigate the potential involvement of ADI in the ability of the SLAB51 to inhibit NOS2 activity, formamidine, a specific inhibitor of ADI was used [13]. The preincubation of SLAB51 with formamidine completely abrogated the ability of SLAB51 to inhibit NO production, bringing back the nitrite value to the control level. Cell exposure to formamidine alone did not affect nitrite levels, excluding the fact that formamidine could directly influence NOS2 activity. 
a

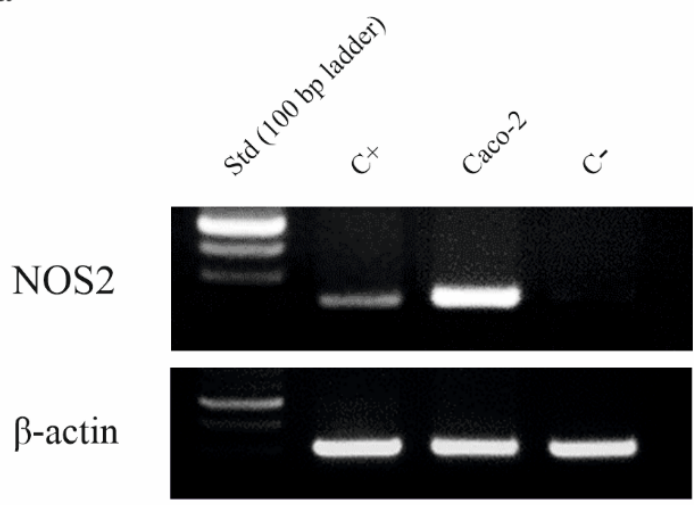

b

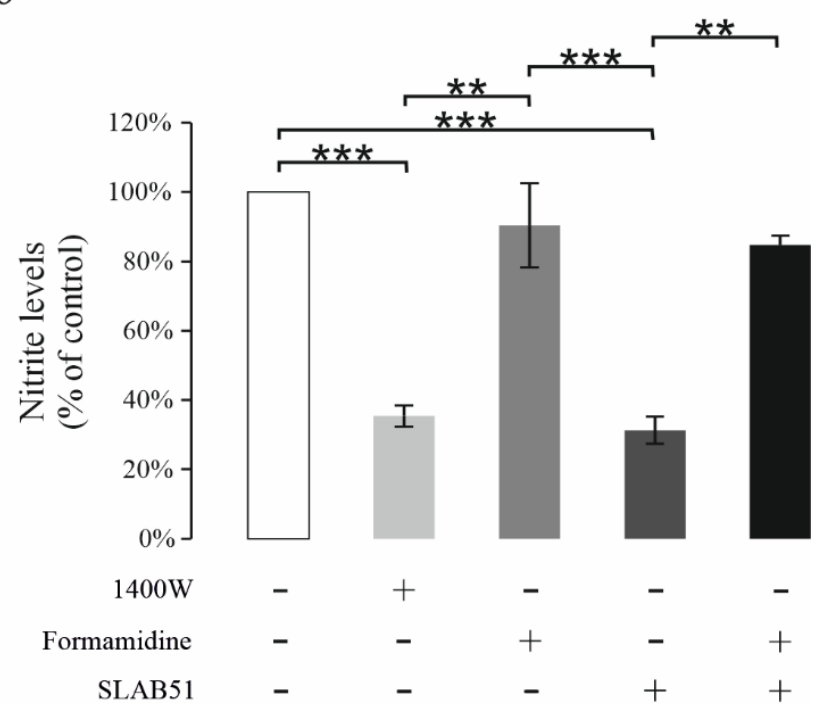

Figure 4. Effect of SLAB51 on NO production in CaCo-2 cells. CaCo-2 cells basically expressed high levels of NOS2 as shown in the representative RT-PCR (a). C+: positive control (RAW cells stimulated with IFN- $\gamma+$ LPS); C- = negative control (Jurkat cells). Nitrite levels were determined in the supernatants from CaCo-2 cells treated for $24 \mathrm{~h}$ (b) with or without NOS2 inhibitor $1400 \mathrm{~W}(100 \mu \mathrm{M})$, ADI inhibitor formamidine $(10 \mathrm{mM})$ or SLAB51 $\left(10^{7} \mathrm{CFU}\right)$ preincubated for 30 min with or without formamidine. Values are expressed as percentage of nitrite levels vs. control (mean $\pm \mathrm{SD}$ ). For comparative analysis of data groups, the Kruskal-Wallis test followed by Dunn's post hoc test was used $\left({ }^{* *} p<0.01,{ }^{* * *} p<0.001\right)$.

\section{Discussion}

The COVID-19 disease is characterized by extremely variable outcomes ranging from the complete absence of symptoms to severe pneumonia and acute respiratory distress syndrome (ARDS) [14]. Under these clinical conditions, mechanical ventilation might become a needed choice. The objective is to give the body as much oxygen as possible, so the brain, heart and kidneys maintain efficiency while waiting for the lungs to heal. Unfortunately, prolonged mechanical ventilation can exacerbate lung dysfunction. Overdistention from high tidal volumes increases airway pressure, or inadequate positive end-expiratory pressure may cause ventilator-induced lung injury. The damage of the alveolar-capillary barrier activates mediators and inflammatory cells that may further increase the biotrauma of COVID-19 patients, especially if they are elderly and with pre-existing organ diseases. Therefore, it is clear that every opportunity to avoid mechanical ventilation is to be considered [15]. Our group supports the use of oral bacteriotherapy as adjuvant therapy for the management of COVID-19 subjects $[4,5]$. The data presented in this paper confirm its utility in two groups of patients initially comparable in terms of clinical, respiratory and laboratory parameters. After $24 \mathrm{~h}$, from the start of bacteriotherapy, the group treated with SLAB51 presented improved blood oxygenation compared to the group receiving only RUT, as evidenced by the analysis of $\mathrm{pO}_{2}, \mathrm{O}_{2} \mathrm{Hb}$ and $\mathrm{SaO}_{2}$ values. This improvement in oxygenation parameter coupled with the feeling of well-being reported by several patients supplemented with SLAB51. Notably, although the group treated with only RUT was supplied with significantly increased amounts of oxygen during the $24 \mathrm{~h}$ observation period, at the endpoint, it presented substantially lower blood oxygenation than that observed for the RUT+OB one. According to surface tension and La Place's law, during ARDS and pneumonia, the alveoli tend to become flooded entirely or not flooded at all. External oxygen furniture to increase the $\mathrm{O}_{2}$ quantity provided to the patient may not guarantee the hypoxemia resolution. The amount of absorbed oxygen is limited mainly by the finite gas exchange capability of damaged alveoli, combined with the reduced number of alveolar cells effectively working in COVID-19 compromised lungs. Consequently, the significantly lower $\mathrm{pO}_{2} / \mathrm{FiO}_{2}$ ratio registered values, at $24 \mathrm{~h}$, for the RUT group confirms the tendency to a worsening of hypoxemia when only the standard therapy is administered. Previously 
published studies suggest that the recovery of lung injury associated with COVID-19 is slow and that, in severely ill patients, pulmonary troubles can persist for a long time after hospital discharge $[16,17]$. The subjects enrolled in our study had a CT lung involvement $\geq 50 \%$. Figure 5 displays the exemplificative CT scan pictures relative to two patients randomly chosen within the whole analyzed population. It is common clinical knowledge that an effective lung recovery certainly takes more than hours in these conditions. The improvement of the oxygenation parameters within a few hours from the administration of SLAB51 suggests that this product modulates the blood consumption of oxygen in the gut. Less oxygen consumption by the intestinal cells results in more oxygen available for other organs.
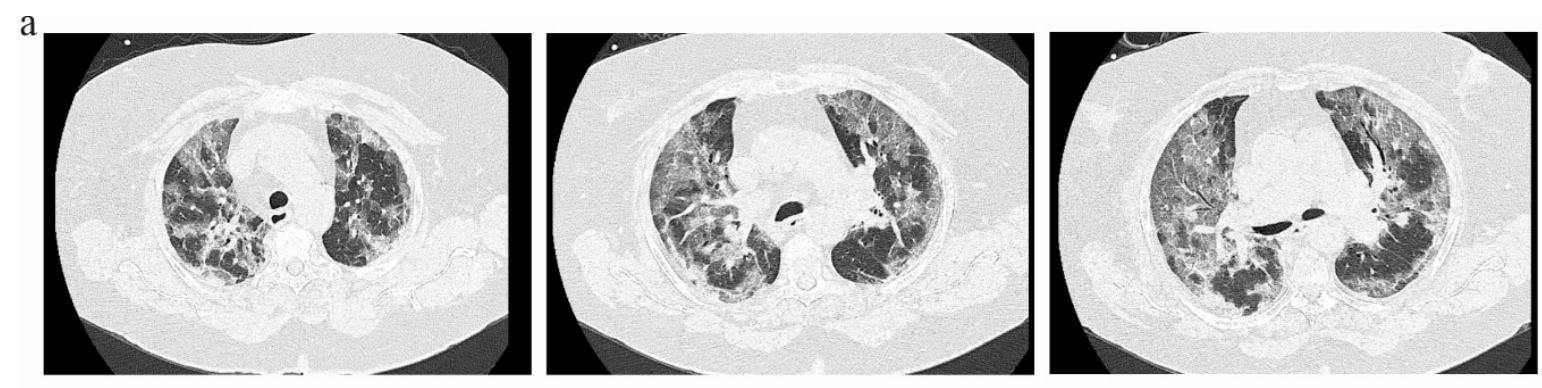

Conclusions of medical report: multifocal and bilateral COVID-19-related interstitial pneumonia in progressive/consolidative phase with parenchymal involvement $>50 \%$.
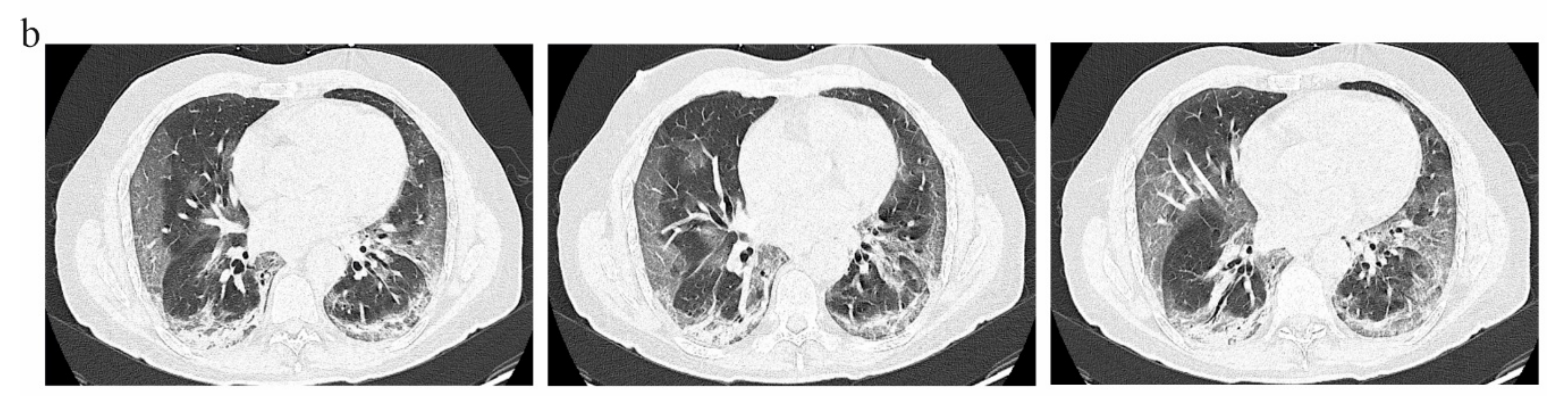

Conclusions of medical report: CT picture compatible with interstitial pneumonia from SARS-CoV2 with the involvement of lung parenchyma estimated at around $50 \%$.

Figure 5. CT lung scan pictures of two randomly chosen COVID-19 patients $(\mathbf{a}, \mathbf{b})$ enrolled in the study.

The estimated surface area of the gastrointestinal tract is around $250-300 \mathrm{~m}^{2}$, and under normal conditions, the intestinal mucosa receives between $10 \%$ and $35 \%$ of the total cardiac output [18]. Our in vitro assays evidenced that the bacteria in SLAB51 are characterized by high ADI activity and are associated with a significant short-time reduction in the NO produced by cells mimicking the intestinal epithelia. ADI catalyzes L-arginine's hydrolysis to citrulline and ammonia and inhibits the arginine-dependent synthesis of NO (Figure 6). Nitric oxide is one of the main regulators of gut mucosal vasodilation [19,20]. Increased NO levels have been associated with the inhibition of hypoxia-inducible factors (HIFs) through a previously determined oxygen-consuming mechanism [21]. The intestinal dysbiosis reported in COVID-19 infected patients might dysregulate NO's production at the intestinal epithelium level [22]. It is known that NO overproduction leads to animal morbidity and death in experimental models of influenza virus infection characterized by a state of pulmonary hyperinflammation [23].

In this context, we speculate that the administration of SLAB51 could produce a relevant inhibition of the NOS2 activity that, by limiting the blood afflux and the oxygen usage in the gut, increases the amount of $\mathrm{O}_{2}$ available in the arterial blood for the brain, kidney and heart. Notably, in patients with hepatitis $\mathrm{C}$ virus $(\mathrm{HCV})$ infection with hepatocellular carcinoma, pegylated arginine deiminase (ADI-PEG 20) treatment induced NO reduction [24]. Although the inhibition of NOS2 activity in the $\mathrm{CaCo} 2$ cell model 
represents a first piece of important evidence about the molecular mechanisms supporting a reduced $\mathrm{O}_{2}$ consumption in the intestine, further in vitro analyses on additional cell lines are needed to confirm our result. In short, we hypothesize that SLAB51 activates an "oxygen sparing effect" detectable by the blood gas analysis and making it clinically relevant. We did not evaluate the number of bacteria reaching the different gut districts after SLAB51 administration or the fecal flora changes. However, we believe that the "oxygen sparing effect" of SLAB51 starts from the upper intestine where only a limited amount of microorganisms are present, making it possible for SLAB51 to act without the interference and competition of the massive bacterial populations present in the colon [25]. Besides, ingested foods do not reach the colon until 8-10 $\mathrm{h}$ later, and we registered the SLAB51 in some of our patients before this.

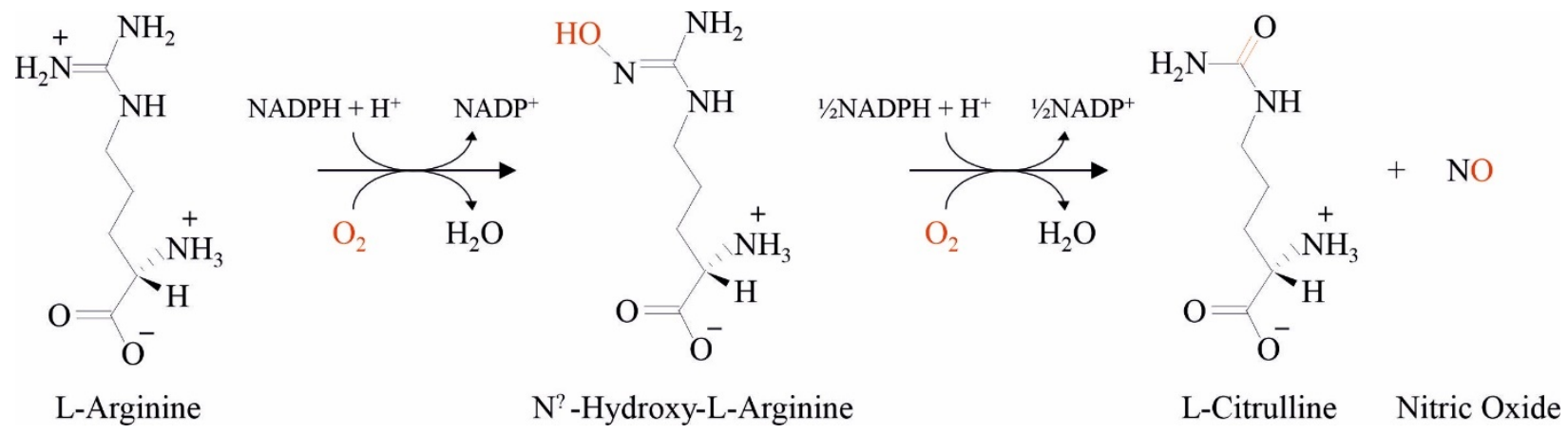

Figure 6. Biochemical reaction describing the catalytic activity of NOS in NO formation. The reaction consumes 1.5 mol of NADPH and 2 mol of oxygen.

\section{Conclusions}

A consistent number of SARS-CoV-2 infected subjects need hospitalization for lesions affecting more than $50 \%$ of the lungs. In COVID-19 patients, as the alveoli swelling worsens, it becomes more difficult for the body to absorb oxygen. Depending on various co-factors such as age, lifestyle, diabetes, cardiovascular diseases, etc., the reduced gas exchange interface is accompanied by progressive damage to the body's organs, in some cases, facilitating the progression of the conditions up to death. SLAB51 contains ADI, which is useful in contrasting the viral infection and mitigating the COVID-19-associated inflammatory status [4-6]. While waiting for the lung to recuperate its functions, the "oxygen sparing effect" of SLAB51 might be useful in the time-sensitive race to maintain oxygenation at sufficient levels and reduce the need for intensive care admissions. Additional trials must reconfirm our results, and at the same time we underline that the reproducibility of the results obtained is related to the experimental conditions described and is not extensible "a priori" to probiotics other than the one used in this study [26].

Author Contributions: Conceptualization, G.C., G.d., C.M.M., F.P., M.M. (Massimo Mancone), V.T.; Methodology, L.C., F.L., A.P.; Investigation, L.C., F.L., A.P.; Formal analysis, M.M. (Massimiliano Marazzato); Writing-original draft, G.C., G.d., M.M. (Massimiliano Marazzato). All authors have read and agreed to the published version of the manuscript.

Funding: This research received no external funding.

Institutional Review Board Statement: Reporting of the study conforms to broad EQUATOR guidelines. The Ethics Committee of Policlinico Umberto I approved the study with number 109/2020.

Informed Consent Statement: Informed consent was obtained from all subjects involved in the study.

Data Availability Statement: Data about investigated patients and analytic methods will not be made publicly available.

Acknowledgments: The authors wish to thank Claudio De Simone for suggesting the rationale of the study and the dosage of administered oral bacteriotherapy. We thank all those in the Intensive 
Care COVID-19 Study Group and in the Infectious Diseases COVID-19 Study Group of La Sapienza University of Rome who assisted in the care of the patients in this program.

Conflicts of Interest: The authors declare no conflict of interest.

\section{References}

1. Sundararaman, A.; Ray, M.; Ravindra, P.V.; Halami, P.M. Role of probiotics to combat viral infections with emphasis on COVID-19. Appl Microbiol. Biotechnol. 2020, 104, 8089-8104. [CrossRef]

2. Giannoni, E.; Baud, D.; Agri, V.D.; Gibson, G.R.; Reid, G. Probiotics and COVID-19. Lancet Gastroenterol. Hepatol. 2020, 5, 720-721. [CrossRef]

3. Baud, D.; Dimopoulou Agri, V.; Gibson, G.R.; Reid, G.; Giannoni, E. Using Probiotics to Flatten the Curve of Coronavirus Disease COVID-2019 Pandemic. Front. Public Health. 2020, 8, 186. [CrossRef]

4. Ceccarelli, G.; Borrazzo, C.; Pinacchio, C.; Santinelli, L.; Innocenti, G.P.; Cavallari, E.N.; Celani, L.; Marazzato, M.; Alessandri, F.; Ruberto, F.; et al. Oral Bacteriotherapy in Patients With COVID-19: A Retrospective Cohort Study. Front. Nutr. 2021, 7, 613928. [CrossRef]

5. d'Ettorre, G.; Ceccarelli, G.; Marazzato, M.; Campagna, G.; Pinacchio, C.; Alessandri, F.; Ruberto, F.; Rossi, G.; Celani, L.; Scagnolari, C.; et al. Challenges in the Management of SARS-CoV2 Infection: The Role of Oral Bacteriotherapy as Complementary Therapeutic Strategy to Avoid the Progression of COVID-19. Front. Med. 2020, 7, 389. [CrossRef]

6. Grimes, J.M.; Khan, S.; Badeaux, M.; Rao, R.M.; Rowlinson, S.W.; Carvajal, R.D. Arginine depletion as a therapeutic approach for patients with COVID-19. Int J. Infect. Dis. 2021, 102, 566-570. [CrossRef] [PubMed]

7. Xu, Z.; Shi, L.; Wang, Y.; Zhang, J.; Huang, L.; Zhang, C.; Liu, S.; Zhao, P.; Liu, H.; Zhu, L.; et al. Pathological findings of COVID-19 associated with acute respiratory distress syndrome. Lancet Respir Med. 2020, 8, 420-422. [CrossRef]

8. Abruzzo, A.; Vitali, B.; Lombardi, F.; Guerrini, L.; Cinque, B.; Parolin, C.; Bigucci, F.; Cerchiara, T.; Arbizzani, C.; Gallucci, M.C.; et al. Mucoadhesive Buccal Films for Local Delivery of Lactobacillus brevis. Pharmaceutics 2020, 12, 41. [CrossRef] [PubMed]

9. Palumbo, P.; Miconi, G.; Cinque, B.; Lombardi, F.; La Torre, C.; Dehcordi, S.R.; Galzio, R.; Cimini, A.; Giordano, A.; Cifone, M.G. NOS2 expression in glioma cell lines and glioma primary cell cultures: Correlation with neurosphere generation and SOX-2 expression. Oncotarget 2017, 8, 25582-25598. [CrossRef] [PubMed]

10. R Core Team. R: A Language and Environment for Statistical Computing; R Foundation for Statistical Computing: Vienna, Austria, 2014; Available online: http:/ / www.R-project.org/ (accessed on 1 May 2021).

11. Panaro, M.A.; Carofiglio, V.; Acquafredda, A.; Cavallo, P.; Cianciulli, A. Anti-inflammatory effects of resveratrol occur via inhibition of lipopolysaccharide-induced NF-кB activation in Caco-2 and SW480 human colon cancer cells. Br. J. Nutr. 2012, 108, 1623-1632. [CrossRef]

12. Palumbo, P.; Lombardi, F.; Augello, F.R.; Giusti, I.; Luzzi, S.; Dolo, V.; Cifone, M.G.; Cinque, B. NOS2 inhibitor 1400 W Induces Autophagic Flux and Influences Extracellular Vesicle Profile in Human Glioblastoma U87MG Cell Line. Int J. Mol. Sci. 2019, 20, 3010. [CrossRef]

13. Riccia, D.N.; Bizzini, F.; Perilli, M.G.; Polimeni, A.; Trinchieri, V.; Amicosante, G.; Cifone, M.G. Anti-inflammatory effects of Lactobacillus brevis (CD2) on periodontal disease. Oral Dis. 2007, 13, 376-385. [CrossRef]

14. Rabi, F.A.; Al Zoubi, M.S.; Kasasbeh, G.A.; Salameh, D.M.; Al-Nasser, A.D. SARS-CoV-2 and Coronavirus Disease 2019: What We Know So Far. Pathogens 2020, 9, 231. [CrossRef]

15. Mach, W.J.; Thimmesch, A.R.; Pierce, J.T.; Pierce, J.D. Consequences of hyperoxia and the toxicity of oxygen in the lung. Nurs Res. Pract. 2011, 2011, 260482. [CrossRef]

16. Huang, C.; Huang, L.; Wang, Y.; Li, X.; Ren, L.; Gu, X.; Kang, L.; Guo, L.; Liu, M.; Zhou, X.; et al. 6-month consequences of COVID-19 in patients discharged from hospital: A cohort study. Lancet 2021, 397, 220-232. [CrossRef]

17. Bellan, M.; Soddu, D.; Balbo, P.E.; Baricich, A.; Zeppegno, P.; Avanzi, G.C.; Baldon, G.; Bartolomei, G.; Battaglia, M.; Battistini, S.; et al. Respiratory and Psychophysical Sequelae Among Patients with COVID-19 Four Months after Hospital Discharge. JAMA Netw. Open 2021, 4, e2036142. [CrossRef] [PubMed]

18. Lundquist, P.; Artursson, P. Oral absorption of peptides and nanoparticles across the human intestine: Opportunities, limitations and studies in human tissues. Adv. Drug Deliv. Rev. 2016, 106 Pt B, 256-276. [CrossRef]

19. Moncada, S.; Palmer, R.M.; Higgs, E.A. The discovery of nitric oxide as the endogenous nitrovasodilator. Hypertension 1988, 12 , 365-372. [CrossRef] [PubMed]

20. Ignarro, L.J. Nitric oxide as a unique signaling molecule in the vascular system: A historical overview. J. Physiol. Pharmacol. 2002, 53 Pt 1, 503-514. [PubMed]

21. Singhal, R.; Shah, Y.M. Oxygen battle in the gut: Hypoxia and hypoxia-inducible factors in metabolic and inflammatory responses in the intestine. J. Biol. Chem. 2020, 295, 10493-10505. [CrossRef] [PubMed]

22. Zuo, T.; Zhang, F.; Lui, G.C.Y.; Yeoh, Y.K.; Li, A.Y.L.; Zhan, H.; Wan, Y.; Chung, A.C.K.; Cheung, C.P.; Chen, N.; et al. Alterations in Gut Microbiota of Patients With COVID-19 During Time of Hospitalization. Gastroenterology 2020, 159, 944-955.e8. [CrossRef]

23. Perrone, L.A.; Belser, J.A.; Wadford, D.A.; Katz, J.M.; Tumpey, T.M. Inducible nitric oxide contributes to viral pathogenesis following highly pathogenic influenza virus infection in mice. J. Infect. Dis. 2013, 207, 1576-1584. [CrossRef] [PubMed] 
24. Izzo, F.; Marra, P.; Beneduce, G.; Castello, G.; Vallone, P.; De Rosa, V.; Cremona, F.; Ensor, C.M.; Holtsberg, F.W.; Bomalaski, J.S.; et al. Pegylated arginine deiminase treatment of patients with unresectable hepatocellular carcinoma: Results from phase I/II studies. J. Clin. Oncol. 2004, 22, 1815-1822. [CrossRef] [PubMed]

25. Sekirov, I.; Russell, S.L.; Antunes, L.C.; Finlay, B.B. Gut microbiota in health and disease. Physiol. Rev. 2010, 90, 859-904. [CrossRef] [PubMed]

26. Ceccarelli, G.; Scagnolari, C.; Pugliese, F.; Mastroianni, C.M.; D’Ettorre, G. Probiotics and COVID-19. Lancet Gastroenterol. Hepatol. 2020, 5, 721-722. [CrossRef] 